\title{
LUGAR, REGIÃo, NAÇÃO, MUNDO \\ EXPLORAÇÕES HistóRICAS DO DEBATE \\ ACERCa das Escalas da AÇÃo Política
}

\author{
CARLOS B. VAINER
}

R E S U M O A partir de uma revisão teórica da noção de escala e de uma recuperação do debate socialista no século XIX a respeito de nacionalismo e internacionalismo, o artigo pretende lançar um novo olhar sobre a discussão contemporânea acerca da escala pertinente da ação politica e do planejamento. Rejeitando a possibilidade de que qualquer estratégia efetivamente transformadora se inscreva numa única e privilegiada escala - local, regional, nacional ou global-, a conclusão sugere que o poder, mais do que nunca, não está nem no local nem no regional, nem no nacional nem no global... mas na capacidade de articular escalas, de analisar e intervir de modo transescalar.

P A L A V R A S - C H A V E Escala; planejamento; ação política.

\section{NTRODUÇÃO}

A questão que se pretende explorar neste trabalho emergiu lentamente a partir de um conjunto de pesquisas e reflexóes, e, por assim dizer, tem vários pontos de partida. Penso ser necessário esclarecer que pontos de partida são esses, de maneira a deixar claro do que se fala e a partir de onde se fala.

\section{PRIMEIRO PONTO DE PARTIDA}

Um primeiro ponto de partida se instaura na simples observação da produção científica na área dos estudos urbanos e regionais, de início, mas também nas várias disciplinas que contribuem para a constituição dessa área: Economia, Ciência Política, Geografia, Sociologia, Antropologia. A todo tempo o tema das escalas comparece nos discursos teóricos que buscam dar conta do que constituiria a essência da contemporaneidade, ou, se preferir, das formas contemporâneas do capitalismo. Se é verdade que, salvo raras exceções, a palavra escala somente figura na produção dos geógrafos, o fato é que a questão se faz presente por uma série de outras expressões na produção atual das Ciências Sociais em geral. Globalização, blocos regionais (Nafta, União Européia, Mercosul), desenvolvimento local, poder local, dissolução das fronteiras nacionais e enfraquecimento do Estado-nação, patriotismo de cidade, competição entre lugares e cidades, até mesmo império (Hardt \& Negri, 2001), essas, entre outras, são expressões que têm freqüentado com grande intensidade os trabalhos e os encontros acadêmicos. Um levantamento nos currículos dos cursos de Planejamento Urbano e Regional, assim como dos trabalhos apresentados, mesas e conferências nos encontros científicos, daria uma boa indicação da onipresença da questão no campo intelectual em referência.
1 Uma primeira versão deste trabalho foi apresentada, como conferência, no Concurso Público de Provas e Títulos para Professor Titular em Planejamento Urbano e Regional, no IPPUR/UFRJ, em junho de 2005. 
L U G A R , $\quad$ R E $\quad$ G I

Essas categorias e expressões aparecem recorrentemente também no discurso político, sugerindo fortemente que tanto o debate sobre as características do capitalismo contemporâneo e suas implicações societárias como a discussão acerca de caminhos e/ou alternativas vêm-se desenrolando, em boa medida, sob a égide de categorias e problemáticas escalares.

Finalmente, como que a consagrar a sua atualidade, cabe lembrar que o tema e seu vocabulário conexo comparecem com igual intensidade na mídia, mostrando que já transcenderam de muito o universo dos especialistas, cientistas e políticos, analistas e praticantes da ação política. Para matar a curiosidade, fiz uma rápida e despretensiosa pesquisa nas edições do jornal Folha de S.Paulo do mês de setembro (2005): a palavra "globalização" apareceu 32 vezes, assim distribuídas nas diversas seçōes: "Dinheiro", dez vezes; "Ilustrada", dez vezes (gastronomia, livros, assuntos gerais); "Mundo", cinco vezes; "Mais!", duas vezes; "Cadernos Especiais", duas vezes; "Brasil”, uma vez; "Esportes”, uma vez; "Empregos", uma vez. No jornal $O$ Globo, no mesmo período, o termo "globalização" apareceu 26 vezes, igualmente distribuídos da editoria de "Economia" até a editoria do "Caderno Elas". Certamente não há como pôr em dúvida a força da presença do tema da escala e das categorias escalares nos dias que correm.

\section{SEGUNDO PONTO DE PARTIDA}

O segundo ponto de partida vem das pesquisas que tenho desenvolvido nos últimos anos, seja na área das políticas energéticas e impactos de grandes projetos hidrelétricos, seja na área dos modelos de planejamento urbano ou dos movimentos sociais comparados. Estudando grandes projetos hidrelétricos ou grandes projetos urbanos, buscando comparar movimentos sociais, em cada projeto de pesquisa temos estado confrontados à necessidade de examinar como se articulam dinâmicas e tendências, agências e estruturas, conjunturas e sujeitos que operam e interagem em diferentes escalas. Como identificar singularidades e generalidades? Quais as potencialidades heurísticas de estudos de caso? Estarão eles condenados a perder o sentido em virtude da homogeneização imposta pela globalização? Ou estarão submetidos à mesma condenação, mas pela razão inversa de que toda comparação e generalização é impossível num mundo feito de singularidades, real fragmentado insuscetível de qualquer narrativa abrangente? Estaremos condenados a sofrer o vaticínio de Milton Santos: "Quem não entende tudo, não entende nada?". Mas, nesse caso, de que totalidade se trata?

E qual a contribuição dos estudos comparados? Será que o máximo a que se pode almejar é o reducionismo do comparatismo globalizado das agências multilaterais, feito de indicadores que só indicam o que já se sabe e escamoteiam exatamente o que é necessário desvelar? Estarão os planejadores condenados à miséria empobrecedora dos concursinhos de best practices? Ou algo de promissor e fértil poderá resultar da multiplicação de relações acadêmicas internacionais propiciada pelas redes e associações que conformam uma comunidade acadêmico-científica global? Poderão os estudos comparados nos ensinar alguma coisa, numa contemporaneidade que a tudo homogeneiza, ao mesmo tempo que, segundo alguns, favorece, como pós-modernidade vitoriosa, todas as fragmentaçóes e tribalizações, para usar uma expressão cara a Castells?

Em particular, quando me engajei em um ambicioso projeto de pesquisa sobre Movimentos Sociais Comparados - Brasil, África do Sul, Índia e Tailândia -, colocávamos 
algumas perguntas que atualizam, de outra forma, a mesma questão da escala. Como respondem aos processos contemporâneos de globalização os diferentes movimentos sociais e organizações não-governamentais, herdeiros de tradições e culturas políticas diversificadas, enraizados em realidades locais e nacionais tão diversas? Serão capazes de elaborar agendas, canais de comunicação e formas de organização que combinem diversidade e unidade? Dito em outros termos: serão capazes de articular práticas nas escalas local, regional, nacional e internacional/global? Estarão aptos a conceber e levar adiante, como sugeriu Bourdieu (1998), um novo internacionalismo?

Ou terão razão autores anglo-saxões, muitos dos quais se reivindicam pesquisadoresativistas ou ativistas-pesquisadores, e também alguns brasileiros, como o saudoso Octavio Ianni, ao afirmarem que esse novo internacionalismo já se está instaurando por meio das redes transnacionais de defesa de direitos humanos, ambientais, de gênero, etnia etc., que prenunciam a constituição de uma autêntica sociedade civil global e a afirmação de uma cidadania global?

Em síntese, por vários caminhos e de várias maneiras, a questão da "escala da agência”, e particularmente a "escala da ação política", parece ser crucial tanto para aqueles que querem compreender o mundo contemporâneo quanto para aqueles que querem transformá-lo... na suposição, já criticada por Marx, de que seja possível compreender o mundo sem o compromisso de transformá-lo (Teses sobre Feuerbach), e na suposição, já desmoralizada por Lenin, de que seja possível transformar o mundo sem compreendê-lo ("Não há prática revolucionária sem teoria revolucionária”).

\section{TERCEIRO PONTO DE PARTIDA - A RELEVÂNCIA DO TEMA PARA OS PLANEJADORES}

Para os planejadores urbanos e regionais, a questão se coloca de forma inescapável: qual a escala adequada de planejamento? Faz sentido insistir no planejamento regional ou local quando os processos de decisão que determinam a estruturação, a reprodução ou a transformação do espaço ocorrem em nível nacional e, mesmo, cada vez mais, em âmbito global/internacional? Em caso negativo, o que fazer? Ou, será que, pelo contrário, justamente em virtude da impossibilidade de interferir nos processos decisórios monopolizados por um punhado de global players, a ação local constitui, hoje, a trincheira última da democracia, da cidadania e da sociedade, como já sugeriu Castells (1990)? Como pensar e confrontar (se for o caso) as teorias e práticas do planejamento quando o Banco Mundial, o PNUD, o BID e outras agências multilaterais, que escapam ao controle da maioria dos Estados nacionais (não de todos, sabemos), constituem, de fato, os principais núcleos de concepção, elaboração, difusão e implementação (por meio de créditos condicionados) de conceitos, modelos, procedimentos? Idéias fora de lugar? Mas de que lugar se está falando?

Uma reflexão sobre a escala do planejamento faz-se mais que necessária, se não queremos sucumbir a uma atitude passiva, reativa, que transforma a teoria e a prática do Planejamento em mero mecanismo de tradução dos modelos, de vernaculização de procedimentos e práticas. E, como é notório, mesmo essa vernaculização parece incapaz de realizar-se plenamente, como se constata até mesmo nas linguagens adotadas: empoderamento, parcerias, governança, entre outros termos, imposição da língua franca da globalização aos vernáculos periféricos. Sem pretender reviver Policarpo Quaresma em defesa da língua pátria e propor o banimento das expressóes estrangeiras de nosso convívio vocabular, evidentemente 
L U G A R , $\quad$ R E $\quad$ G I A

há que reconhecer que o uso e abuso dos anglicismos constitui prova da rapidez com que se difundem os modelos e concepções que essas linguagens redesenham e ancoram.

Se o Planejamento, como já sugeriu Francisco de Oliveira, parafraseando Clausewitz, é a política por outros meios, perguntar-se sobre as relaçôes entre escalas de ação planejadora é perguntar-se, ipso facto, sobre as relações entre escalas da ação política.

\section{VELHAS NOVIDADES?}

A questão para a qual despertei, e que pretendo explorar, pode ser formulada de maneira bastante simples. Apesar de o discurso sobre a contemporaneidade, em particular o discurso que opera de maneira recorrente com categorias escalares, insistir que a relevância do tema é uma das características centrais de nosso tempo, defendo a idéia de que em outros momentos da história as escalas ocuparam lugar tão ou mais relevante no debate teórico e político. Em outros termos: não é a primeira vez que as categorias escalares e as escalas da ação política alcançam centralidade do debate teórico e político.

Tomando o século XIX como referência, penso ser possível mostrar quão ricas foram as elaboraçōes e acaloradas discussōes, entre militantes e intelectuais progressistas e revolucionários, sobre o local, o nacional, o internacional. E penso também que muitas das perguntas então enfrentadas, e não totalmente resolvidas, continuam a interpelar analistas e militantes acerca do que proponho chamar de escala pertinente de análise e de escala pertinente de ação política. Esse o sentido destas explorações históricas.

Assim, o que fiz foi selecionar alguns momentos particularmente críticos da elaboração do pensamento acerca da questão do nacionalismo e do internacionalismo na tradição do pensamento marxista na segunda metade do século XIX e no início do século XX.

Antes, porém, de apresentar os resultados iniciais de minhas exploraçôes históricas que nos remeterão, para começar, a 1848, peço a paciência do leitor para alguns comentários preliminares, o mais sintéticos que possível, sobre a noção de escala e sobre a possibilidade e sentido de realizar a leitura histórica dessa categoria que é, essencialmente, geográfica. Vamos, pois, iniciar com algumas "explorações conceituais".

\section{AS ESCALAS - EXPLORAÇÕES CONCEITUAIS}

Como já assinalei, o debate estritamente acerca do conceito escala é praticamente um debate entre geógrafos. O que nos dizem os geógrafos?

\section{ESCALA CARTOGRÁFICA E ESCALA COMO PERSPECTIVA}

Seguindo Castro (2005, p.117), podemos inicialmente reconhecer dois grandes campos. O primeiro campo seria constituído por todos aqueles que acionam a noção cartográfica de escala: "uma fração que indica a relação entre as medidas do real e aquelas de sua representação gráfica”. O outro campo remeteria a diferentes "modos de concepção e percepção do real" (ibidem, p.118). Nesse caso, em vez de uma mera medida, a escala compõe, ou integra, uma "estratégia de aproximação do real" (ibidem) ou de "apreensão da realidade" (ibidem, p.120), "uma maneira de contemplar o mundo e de torná-lo visível" (ibidem, p.127). 


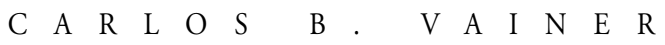

Nessa segunda concepção, instrumento operacional à disposição do pesquisador, de cuja sensibilidade e competência depende a capacidade de adotar a escala pertinente para observar o fenômeno ou processo estudados, lidamos com a "escolha de uma forma de dividir o espaço, definindo uma realidade concebida/percebida, é uma forma de dar-lhe uma figuração, uma representação, um ponto de vista" (ibidem, p.136).

Estamos, pois, diante de um perspectivismo no qual a escala conota ou define um "ponto de vista" (ibidem, p.136). Em texto posterior, apoiada em Merleau-Ponty, Castro (1997, p.36) vai construir uma relação entre escala e fenômeno estudado bem menos linear. Superando a visão empirista de que para cada fenômeno há uma escala adequada, vai dar-se conta de que "a escala de observação [também] define o fenômeno".

Lacoste (1976, p.63), em seu clássico texto-manifesto, adota a mesma concepção perspectivista, embora destaque com grande ênfase que entre

mapas de escalas desiguais não há apenas diferenças quantitativas, segundo o tamanho do espaço representado, mas também diferenças qualitativas, pois um fenômeno não pode ser representado senão em uma determinada escala ... em outras escalas ou bem ele não é representável, ou seu significado é modificado ... Eis um problema essencial, mas difícil.

O que parece mais importante no manifesto lacostiano, porém, é a enfática denúncia da ingênua ilusão da "geografia dos professores" de que opções escalares possam resultar de operações assépticas e neutras. Ao contrário, dizia ele: "No plano não mais do conhecimento, mas da ação (urbanística ou militar) existem níveis de análise que cabe privilegiar, pois eles correspondem a espaços operacionais, em razão das estratégias e táticas acionadas" (ibidem, p.67).

Em Lacoste, porém, a escala ainda permanece associada à problemática da representação e da extensão. E, nesse sentido, continua sendo uma forma de recortar extensões.

\section{AS ESCALAS DO CAPITAL}

A chamada Geografia crítica, de que Lacoste pode ser considerado um dos fundadores, foi mais longe na discussão teórica, ultrapassando largamente as duas correntes - numérica/cartográfica e perspectivista/geográfica - reconhecidas por Castro. Seria impossível percorrer toda a abundante produção a respeito. Tomarei Neil Smith como referência, pelo lugar central que ocupa na discussão específica sobre o conceito de escala no campo dos geógrafos marxistas - em sua grande maioria de língua inglesa ou escrevendo nessa língua.

A primeira grande ruptura instaurada diz respeito à qualificação mesma do espaço $\mathrm{e}$ das escalas espaciais de que se fala. Trata-se agora, sem dúvida, do espaço sob capital, do espaço da acumulação do capital, e das escalas em que esse processo ocorre e as escalas que engendra. $\mathrm{O}$ espaço, assim como as escalas, nesse caso, deixa de ser uma opção ou instrumento operacional do pesquisador, do planejador ou do chefe de Estado maior, para ser reconhecido como socialmente construído e, pour cause, historicamente determinado:

para se compreender completamente o desenvolvimento desigual do capitalismo, seria necessário entender-se a origem das escalas geográficas. Geralmente tendemos [a] considerar como questão indiscutível a divisão do mundo em alguma combinação de escalas - urbana, regional, nacional e internacional -, mas raramente explicamos como elas surgiram. (Smith, 1988, p.195.) 
L U G A R , $\quad$ R E $\quad$ G I

E, para Smith, de onde surgem as escalas? Quais as suas origens? Como marxista respeitador dos cânones, Smith vai encontrar as origens das escalas do capital na lógica mesma da acumulação do capital e sua tendência imanente para o desenvolvimento desigual. Eu diria que sua abordagem é histórica somente em certa medida: é verdade que as escalas são históricas no sentido de que se instauram quando, e somente quando, emerge o capital como relação social dominante. Mas também é verdade que, a partir daí, a história como que é subsumida pela lógica do capital. É o movimento lógico-estrutural que move o espaço e suas escalas.

Em outras palavras: o espaço e as escalas sob o capital não são senão o espaço e as escalas do capital, de seu movimento incessante de acumulação:

O capital herda um mundo geográfico ... À medida que a paisagem fica sob o domínio do capital (e se torna cada vez mais funcional para ele ...), estes padrões são agrupados em uma hierarquia cada vez mais sistemática de escalas espaciais. (Ibidem, p.196.)

Ou ainda, no mesmo sentido: "a criação de um espaço-economia é integrado e organizado nessas escalas" (Ibidem, p.197).

Assim constituídas, as escalas não seriam apenas condicionadas ou determinadas pela lógica do capital; mais que isto, "sua coerência interna" e sua "diferenciação" já estão "contidas na estrutura do capital" (ibidem, p.197). Nessas condições, a historicidade das escalas está inscrita, ex ante, na lógica estrutural do capital. Escalas, assim, não são mais que epifenômenos do movimento do capital.

No movimento de sua acumulação, que é necessariamente desenvolvimento desigual, o capital, segundo Smith (1988, p.197), engendra três escalas: o espaço urbano, a escala da Nação-Estado e o espaço global.

O espaço e/ou a escala urbana são vistos como "expressão necessária da centralização do capital produtivo" (ibidem, p.197), o lugar em que se atualiza e espacializa a concentração dos meios de produção e força de trabalho. Se seus limites não podem ser confundidos com a jurisdição administrativa das cidades, eles estão dados de maneira objetiva e evidente: as fronteiras do mercado de trabalho e os "limites ao deslocamento diário para o trabalho" (ibidem).

Quanto ao espaço ou escala global, o capitalismo a define como "escala geográfica global à sua própria imagem” (ibidem, p.202). Nessa escala o capital realiza plenamente sua pulsão homogeneizadora, na medida mesma em que impõe por toda parte a relação capital - trabalho e o valor... mesmo se as escalas nacional e urbana permanentemente impõem barreiras ao processo global de homogeneização.

O que me parece curioso no esquema analítico proposto por Smith é que a escala nacional, ao contrário das outras duas, será definida como uma escala de segunda ordem, já que, à margem da produção, é concebida como espaço da circulação do capital.

Se a escala urbana e a global representam, respectivamente, a perfeita expressão geográfica das tendências contraditórias para a diferenciação e para igualização, a escala da NaçãoEstado é um produto menos direto desta contradição. $\mathrm{O}$ impulso para a produção dessa escala vem da circulação do capital. (Ibidem, p. 204.)

Para os que conhecem a primazia que a esfera da produção (do valor) tem em relação à esfera da circulação nos esquemas de reprodução de Marx, e no pensamento mar- 

C A
R $\quad$ L $\quad \mathrm{O} \quad \mathrm{S}$
B.
$\begin{array}{lllllllllllllll}\mathrm{V} & \mathrm{A} & \mathrm{I} & \mathrm{N} & \mathrm{E} & \mathrm{R}\end{array}$

xista canônico de modo geral, não fica difícil entender a importância relativamente pequena atribuída por Smith a essa escala nacional. Poderíamos nos perguntar se, ao contrário, não foi a desconsideração com essa escala que acabou conduzindo Smith a conferir-lhe papel apenas na esfera da circulação.

Relativamente desimportante do ponto de vista que interessa, isto é, do ponto de vista do movimento da acumulação do capital, centralização do capital, homogeneização e diferenciação que caracterizam o desenvolvimento desigual do capital, a escala nacional é relegada ao que, no passado, e ainda hoje, os marxistas ortodoxos vêem como superestrutura: esfera do poder e da reprodução da dominação. Dando um pobre e a-histórico tratamento funcionalista-utilitário à questão do Estado-nação, Smith vê duas razões para a existência do Estado: a defesa contra outros capitais nacionais imobilizados e, além disso, a defesa contra a classe trabalhadora - "de quem há sempre uma permanente ameaça de revolta" (ibidem, p.205).

Poder-se-ia saudar, enfim, a emergência de outras dimensões que não a sempre invocada dimensão do processo de acumulação do capital; mas, na verdade, a ameaça permanente de revolta dos trabalhadores não altera em nada o argumento.

O pensamento aqui analisado traz uma enorme contribuição ao enunciar, com todas as letras, que estamos falando de espaço e de escalas que são históricas, e datam da era do capital. Mas essa entronização do espaço e das escalas na história acaba cobrando um preço alto: as escalas aparecem como não sendo senão expressão da estrutura do capital, da lógica imanente que se expressa no movimento de sua acumulação. A história foi introduzida para imediatamente ser posta de lado: houve história, não há mais. O que temos agora são lógicas estruturais que se manifestam no movimento do capital - e que criam o tempo e o espaço do capital.

Embora não seja possível avançar nessa discussão, cabe destacar que, em trabalho posterior, Smith retomou a discussão sobre as escalas, introduzindo dimensões antes silenciadas, e faz um nova e mais longa listagem de escalas: o corpo, a comunidade, o urbano, o regional, o nacional e o global (Smith, 1993). Apesar de alguns enriquecimentos, permanecem os elementos centrais da análise: a) a reificação das escalas, tidas como dadas objetivamente e impostas aos homens; b) a evidente desconsideração da complexidade histórica e diversidade dos Estados nacionais; c) as escalas como recortes do espaço que contêm umas às outras numa "hierarquia sistemática".

Essa "hierarquia sistemática” retoma algo que já estava presente na literatura geográfica, que é a concepção das escalas como recortes de extensões do espaço que se encaixam umas nas outras, como babuchkas. Assim como as regiōes lablachianas, criticadas por Lacoste, se encaixavam num plano, as escalas dos geógrafos, incluindo Smith, se encaixam. Chamo isso de escalaridade babuchka: cada escala está contida na escala superior e contém a escala inferior. É a volta da noção do espaço como continente de relações e práticas.

\section{A ESCALA DA ECONOMIA-MUNDO CAPITALISTA}

Essa concepção de escalas encaixadas, ordenadas numa hierarquia que ascende do pequeno ao grande, é rompida por Wallerstein (1991). O empreendimento teórico-histórico de Wallerstein é amplo e profundo. Em sua proposta de "despensar a ciência social", ele vai questionar o que considera o mito de origem do capitalismo e da sociedade moderna, mito cuja narrativa seria compartilhada por marxistas e liberais. 
L U G A R , $\quad$ R E $\quad$ G I

Nessa narrativa mitológica, a modernidade aparece como um processo contínuo e ascendente que teria partido do local, passando pelo nacional até chegar ao internacional/global. Esse "mito da história moderna da Europa" (Wallerstein, 1991, p.73) desconheceria o processo de constituição de economia-mundo que instaura, ela sim, a grande ruptura com a Idade Média: "Se o movimento essencial da história moderna da Europa foi do aglomerado urbano para a economia nacional, da arena local pra o Estado nacional, onde entra o 'mundo neste quadro'?" (ibidem, p.73).

Uma outra, e nova, narrativa da origem é proposta:

A transição do feudalismo ao capitalismo envolveu primeiramente (primeiramente do ponto de vista lógico e primeiramente do ponto de vista temporal) a criação de uma economia-mundo. Isto é, a divisão social do trabalho veio à existência através de transformação do comércio de longa distância, que era de bens de luxo, em comércio de bens essenciais ou de massa, vinculando processos que eram largamente dispersos em extensas cadeias mercantis. (...) Tais cadeias já estavam lá no século XVI, antecedem qualquer coisa que pudesse ser chamado de "economias nacionais". Por outro lado, estas cadeias somente poderiam estar seguras através da construção de um sistema interestatal coordenado com as fronteiras de divisão social do trabalho real, a economia-mundo capitalista. Os estados soberanos foram instituições criadas então, no âmbito desse (expansivo) sistema interestatal, foram definidas por ele e derivaram sua legitimidade da combinação de auto-afirmação jurídica e reconhecimento pelo que é a essência do que quer dizer "soberania". (Ibidem, p.73-4.)

Se em Smith é o capital que engendra as escalas, poder-se-ia arriscar um pouco e dizer que em Wallerstein é quase como se a escala - mundo - engendrasse o capital, ou tornasse sua historicidade possível.

Certamente haveria muito a discutir, e muito tem sido discutido, acerca das concepções que, em Wallerstein e outros, desconsideram as importantes diferenças entre capitalismo mercantil e capitalismo tout court, propriamente dito. Também é claro que as propostas de Wallerstein implicam a configuração de uma relação entre local, nacional e internacional/global que não deixa margem acerca da primazia da escala da economia-mundo como única passível de ser arena para um projeto de questionamento da ordem... que é, evidentemente, antes de mais nada, ordem mundial. Mas esta não é, por ora, nossa questão.

Em Wallerstein, pois, cai por terra o encaixamento sistêmico hierarquizado - $b a$ buchka - das escalas dos geógrafos. Claramente, também, a escala deixa de ser porção do espaço, jurisdição - do mercado de trabalho ou de qualquer outro processo ou fenômeno - para se transformar em campo de fluxos e relações -, relaçóes econômicas, por certo, mas também, e de maneira inseparável, relações de poder.

Mas não se poderia cobrar de Wallerstein, assim como cobramos de Smith, que uma vez a historicidade da economia-mundo imposta, tudo o mais não é senão o seu movimento intrínseco?

\section{NARRATIVAS ESCALARES E LUTA PELA IMPOSIÇÃO DE ESCALAS}

Seja como for, tanto em Wallerstein como em Smith, como em muitos dos autores que compóem o campo do pensamento crítico contemporâneo, mais ou menos direta- 
mente inspirados pela matriz marxista de pensamento, encontramos apoio para pensar uma história das escalas. Mas o que me interessa explorar não é propriamente a história da constituição das escalas e de suas inter-relações. O que pretendo é focalizar como se deu o debate acerca da escala pertinente da ação política.

Certamente, há uma relação estreita, e muitas vezes intencionalmente instrumental, entre, de um lado, as narrativas escalares, para utilizar expressão já empregada por Swyngedouw (1997), isto é, análises das relaçōes escalares involucradas em processos sociais, econômicos e políticos, e, de outro lado, as estratégias e propostas de intervenção/ação que privilegiam tais ou quais escalas.

Dito de outra maneira: por trás, ou à frente, de toda proposta de intervenção/ação política está presente, subjacente ou não, explícita ou não, uma concepção escalar do mundo social, isto é, das formas predominantes de produção e reprodução de relações. É evidente que os wallersteinianos defenderão fortemente a irrelevância da ação política na escala nacional. E não surpreende que Smith dê enorme importância às lutas urbanas, mas não consiga identificar nos movimentos nacionalistas senão ideologias conservadoras e estratégias diversionistas que desviam os trabalhadores, mulheres e distintos grupos étnicos ou religiosos de seus verdadeiros inimigos (Smith, 1993).

Penso, com Swyngedouw, que as escalas - de análise e de intervenção - não estão dadas, nem são fixas, nem podem ser reificadas. Antes, devem ser trazidas para o terreno social, incerto e móvel, daquilo que está em disputa. Nem as estruturas e lógicas econômicas nem as heranças históricas em si determinam e instauram escalas.

Não se trata de sugerir que estaríamos diante da indeterminação total e absoluta, tão a gosto dos pós-modernos, impedimento de qualquer teoria abrangente. Certamente, há bases históricas e materiais, generalidades e dinâmicas que estruturam os processos e suas escalas; mas esses processos são também, necessariamente, processos contraditórios, conflituosos, determinados ou condicionados igualmente por embates em torno da legitimação e imposição (simbólica e política, econômica, cultural) de escalas dominantes.

As escalas não são apenas socialmente construídas ou engendradas, como também, e sobretudo, estão permanentemente em questão, campo e objeto de disputas e confrontos entre diferentes agentes que propõem diferentes escalas e em diferentes escalas se dispõem - seja para conservar seja para transformar o mundo e as escalas que o organizam.

Nessa abordagem, é possível superar a reificação que faz das escalas um enquadramento inescapável para os sujeitos políticos. Como bem observou Swyngedouw (19978, p.140), as escalas são produzidas elas mesmas em processos profundamente heterogêneos, conflituais, contestáveis e contestados: "a escala não está nem ontologicamente dada nem é um território geográfico definível a priori nem uma estratégica discursiva neutra politicamente na construção de narrativas".

Bourdieu (1998) foi extremamente feliz ao desvelar a eficácia dos discursos sobre a inevitabilidade da globalização neoliberal como mecanismo para fazer avançar a globalização, numa espécie de profecia auto-realizada - profetas que atuam para que suas profecias se concretizem. Afinal, se todos se convencerem de que o que resta às cidades é competirem umas com as outras, todas as cidades competirão umas com as outras... e a profecia se realizará.

Ora, se tal ou qual processo parece inevitável e sem alternativas, é porque, como disse Bourdieu (1998, p.34), há um poderoso aparato que inculca ideologias e banaliza os processos. Ao eliminar a possibilidade de escolha, esse exercício do poder simbólico lança a política ao lixo da história e nega a própria historicidade do momento vivido - sem 
2 Encontramos uma passagem em Smith que, embora a nosso ver em contraposição ao marco geral de sua análise, vai nessa mesma direção: "as escalas demarcam os espaços do conflito social, o objeto assim como a resolução do conflito" (1993, p.101).

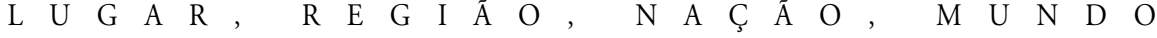

alternativas não há mais história, apenas a reprodução do existente num futuro que, na verdade, já deixou de sê-lo para transformar-se apenas num presente contínuo.

Rejeitar a reificação das escalas e o fim da história permite conceber as escalas como "a arena e o momento, tanto discursiva quanto materialmente, nos quais relações de poder socioespaciais são contestadas, negociadas e reguladas" (Swyngedouw, 1997, p.140).

Assim, é igualmente possível entender que se, de um lado, os confrontos e conflitos ocorrem num mundo escalarmente organizado, de outro, as escalas que organizam o mundo são, elas mesmas, resultantes dos desenlaces de conflitos passados. Para usar a linguagem de Bourdieu, as escalas são estruturadas, mas são também estruturantes.

Assim, as escalas estão dadas, mas sempre em suspenso, posto que objeto de confronto, como também é objeto de confronto a definição das escalas prioritárias onde os embates centrais se darão. ${ }^{2}$

A perspectiva histórica aparece agora decisivamente enriquecida, uma vez que, além dos processos econômicos que subjazem à emergência e desenvolvimento da acumulação do capital, é o próprio embate acerca das escalas que passa a ser contemplado como elemento decisivo. Esse, a meu ver, é o fundamento que autoriza e confere relevância para as explorações históricas que se seguirão acerca das escalas da ação política.

\section{EXPLORAÇÕES HISTÓRICAS - NACIONALISMO E INTERNACIONALISMO NO SÉCULO XIX}

\author{
Capitalismo global e luta Proletária - Proletários de todo o mundo, \\ UNI-VOS ... EM SEUS PAÍSES?
}

Começo com o começo, ou melhor, com o fim do começo, a última frase do Manifesto do Partido Comunista, de 1848: "Proletários de todos os países, uni-vos!". Essa palavra de ordem não poderia ser mais, digamos assim, escalar. De um lado, parte do reconhecimento de que os proletários estão vinculados a países - dirige-se aos proletários dos países, de todos os países. Mas, de outro lado, simultaneamente, diz que o fato de que sejam de diferentes países não pode desviá-los do que é fundamental: devem unir-se. Essa tensão está presente em outras partes do Manifesto e, de certa maneira, no pensamento de Marx e dos marxistas clássicos.

A narrativa escalar do Manifesto sobre o processo histórico é inequívoca. A emergência e o desenvolvimento do capitalismo: a) revolucionou e continua a revolucionar incessantemente o mundo; b) unificou e unifica o mundo sob a égide do capital e da burguesia.

Impelida pela necessidade de mercados sempre novos, a burguesia invade todo o globo. Necessita estabelecer-se em toda parte, explorar em toda parte, criar vínculos em toda parte. Pela exploração do mercado mundial a burguesia imprime um caráter cosmopolita à produção e ao consumo em todos os países. Para desespero dos reacionários, ela retirou à indústria sua base nacional. As velhas indústrias nacionais foram destruídas e continuam a sê-lo diariamente. São suplantadas por novas indústrias, cuja introdução se torna uma questão vital para todas as nações civilizadas, indústrias que não empregam mais matérias-primas autóctones, mas sim matérias-primas vindas das regiōes mais distantes, e cujos produtos se consomem não somente no próprio país mas em todas as partes do globo. Em lugar das antigas necessidades, 

C A $\quad$ R $\quad$ L $\quad$ O
B.
V

satisfeitas pelos produtos nacionais, nascem novas necessidades, que reclamam para sua satisfação os produtos das regiôes mais longínquas e dos climas mais diversos. Em lugar do antigo isolamento de regiōes e nações que se bastavam a si próprias, desenvolve-se um intercâmbio universal, uma universal interdependência das naçôes. E isto se refere tanto à produção material como à produção intelectual. As criaçôes intelectuais de uma nação tornam-se propriedade comum de todas. A estreiteza e o exclusivismo nacionais tornam-se cada vez mais impossíveis; das inúmeras literaturas nacionais e locais, nasce uma literatura universal. (Marx \& Engels, s. d, grifos nossos).

Narrativa escalar acima de tudo, revela-o uma simples contagem semântica: a) as palavras e expressões globo, global, mundial, universal e outras de significado conexo aparecem dez vezes; b) as palavras nação, país e conexas aparecem doze vezes; c) as palavras região e local aparecem quatro vezes.

Se o mundo é um só, e se, sejam quais forem os locais, regiōes, países ou naçōes, o inimigo é o mesmo, nada mais coerente do que convocar para uma luta única todos os proletários. A narrativa escalar sugere uma escala pertinente de análise - o mundo, o mercado e a cultura mundial - e extrai como conseqüência uma escala pertinente de ação política: esse mesmo mundo. Certo? Mais ou menos. Examinemos como nossos autores tratam a questão da relação dos trabalhadores com a nação e com a luta na escala nacional.

Numa instigante passagem, respondendo às acusaçôes de que os comunistas querem abolir a pátria e a nacionalidade, Marx \& Engels (s.d.) escrevem:

Os operários não têm Pátria. Não se lhes pode tirar aquilo que não possuem. Como, porém, o proletariado tem por objetivo conquistar o poder político e erigir-se em classe dirigente da nação, torna-se ele mesmo nação, ele é, nessa medida, nacional, embora de nenhum modo no sentido burguês da palavra.

Passagem, há que reconhecer, um tanto ou quanto obscura. Tanto mais que, logo a seguir, volta o texto a insistir que

As demarcações e os antagonismos nacionais entre os povos desaparecem cada vez mais com o desenvolvimento da burguesia, com a liberdade do comércio e o mercado mundial, com a uniformidade da produção industrial e as condições de existência que lhes correspondem.

Se as demarcações nacionais tendem a desaparecer, por que razão deveria o proletariado constituir-se em classe dirigente da nação?

A explicação, parece-me, é que os autores, apesar da primazia conferida à escala mundial, reconhecem que a luta concreta, aquela na qual de fato o proletariado se constitui como classe, se trava em âmbito nacional. A passagem decisiva seria a seguinte:

A luta do proletariado contra a burguesia, embora não seja na essência uma luta nacional, reveste-se contudo dessa forma nos primeiros tempos. É natural que o proletariado de cada pais deva, antes de tudo, liquidar sua própria burguesia. (Marx \& Engels, s.d., grifos nossos.)

Solução formal e, a meu ver, insatisfatória: como poderia o proletariado nacional liquidar sua própria burguesia se essa já se tornou, há muito, uma força mundial? 
L U G A R , $\quad$ R E $\quad$ G I

Afinal de contas, qual o lugar e qual o papel da escala nacional para Marx \& Engels? Examinando uma série de polêmicas e embates de que participaram, ao longo da segunda metade do século XIX, e que colocavam em questão, de uma maneira ou de outra, a oposição classe versus nação, Georges Haupt (1974, p.12) afirma que, em princípio, em qualquer circunstância, "a posição de Marx e Engels repousa sobre uma certeza absoluta: o primado da classe sobre todas as outras categorias históricas”. Essa posição, que ancoraria a primazia da escala mundial sobre a escala nacional, apoiava-se, sempre segundo Haupt, no entendimento de que a nação não passa de uma categoria transitória que, de um lado, a própria dinâmica do capital tende a enfraquecer e que, de outro, será definitivamente enterrada com a vitória da revolução proletária.

O mesmo autor sugerirá que, ao lado do princípio classista que é, necessariamente, internacionalista, Marx \& Engels operavam também, todo o tempo, com um certo pragmatismo político, o que os levava a oscilar, conforme as conjunturas, no tratamento dado às diferentes reivindicações nacionalistas que espocavam na segunda metade do século XIX.

Assim, por exemplo, seu apoio entusiasmado à independência da Polônia tinha como fundamento sua crença de que a partilha do território polonês entre os Impérios Russo, Austro-Húngaro e a Prússia constituía um dos pilares do despotismo europeu. Mas se a libertação e a reunificação da Polônia pareciam a Marx \& Engels indispensáveis ao avanço das forças progressistas e democráticas, não demonstravam nenhuma simpatia pelo nacionalismo dos povos eslavos dominados pelo Império Austro-Húngaro. Ao contrário, viam sua independência como um fortalecimento da principal trincheira da reação européia, o tsarismo, e do movimento paneslavista que o tsar alimentava e financiava. A respeito de sérvios, croatas, rutênios, montenegrinos e outros, Engels foi implacável, decretando pura e simplesmente seu desaparecimento: "Sou bastante autoritário para considerar como anacrônica a existência, em pleno coração da Europa, de tais povinhos primitivos" (Engels, Carta a Eduard Bernstein, 22.2.1882, apud). Imagine-se o que diria Engels se soubesse que vários desses povinhos primitivos e anacrônicos conquistaram mais de cem anos depois Estados nacionais!

\section{LUTA SOCIALISTA E LUTA NACIONAL - AS RELAÇÕES CENTRO-PERIFERIA}

Há, porém, uma questão em que a posição de Marx foi radicalmente diferente: a questão irlandesa. Para que possam ser percebidos o alcance e a relevância dessa questão, vale a pena destacar que, diferentemente dos casos de poloneses, eslavos do Sul e outros povos submetidos ao Império Otomano, a questão irlandesa colocava em pauta uma relação de dominação em que o pólo dominante era a Inglaterra, vanguarda do desenvolvimento capitalismo, e não um velho e reacionário império autocrático.

O tema do colonialismo, ou, se preferir, da relação centro-periferia, havia sido tratado por Marx em famoso, embora pouco conhecido, artigo sobre a dominação inglesa na Índia, publicado em 1853 no New York Herald Tribune. Após afirmar que a Inglaterra destruíra de maneira profunda e irreversível toda a estrutura da sociedade indiana, Marx (1853) denunciava "que a miséria imposta pelos britânicos no Hindustão é essencialmente diferente e infinitamente mais intensa do que tudo o que jamais sofreu antes o Hindustão". E termina o curto artigo com uma surpreendente conclusão: não importa se os motivos dos ingleses foram torpes e seus crimes, inomináveis, o relevante é que o gê- 
nero humano não alcançará seu destino sem uma revolução social na Ásia, revolução essa deflagrada pelos ingleses que, à sua revelia, se tornaram os instrumentos inconscientes do progresso e da história.

A posição de Marx é conhecida e é inequívoca: os progressos do capitalismo, apesar de sua violência e dos sofrimentos que provoca, são progressos da humanidade como um todo. A globalização capitalista, ou, para utilizar uma linguagem de época, a submissão ao capital dos povos bárbaros e atrasados, é obra do progresso e anuncia o futuro.

Em 1869, 16 anos depois do artigo sobre a Índia, quando o Conselho Geral da Associação Internacional dos Trabalhadores discutia a posição a adotar em relação à ação inglesa na Irlanda, Marx assumiria uma posição diferente e original. Em carta enviada a Engels, Marx escrevia:

Durante muito tempo acreditei que era possível derrubar o regime irlandês [refere-se à dominação inglesa na Irlanda] mediante a influência da classe operária inglesa ... Um estudo mais profundo me convenceu do contrário. A classe operária inglesa não poderá fazer nada antes de liberar-se da Irlanda. Há que apoiar-se na Irlanda. Por este motivo a questão irlandesa é tão importante para o movimento social em geral. (Marx \& Engels, 1979, p.26.)

Em outra carta lê-se:

Anos de estudo sobre a questão irlandesa me levaram à conclusão que o golpe decisivo para o movimento operário de todo o mundo não pode ser dado na Inglaterra, mas somente na Irlanda. (Marx, carta enviada a S. Meyer e A. Vogtn, apud Haupt, 1974, p.97.)

Entre outros argumentos, Marx explicava como a dominação inglesa sobre a Irlanda rebatia-se sobre a classe operária na Inglaterra.

Todos os centros industriais e comerciais da Inglaterra têm agora uma classe operária dividida em dois campos inimigos: proletários ingleses e proletários irlandeses. O operário inglês comum detesta o operário irlandês como um concorrente que abaixa seu padrão de vida. Ele se sente com relação a este como membro de uma nação dominadora e torna-se, assim, o instrumento de seus aristocratas e capitalistas contra a Irlanda, e consolida assim seu poder sobre o outro. (Ibidem H.)

Temos aqui uma posição bastante diversa daquela assumida no tratamento da Índia. Aqui, a questão nacional do país ou nação dominada - ou periférica - se reconfigura do ponto de vista escalar. Não está mais em causa uma simples questão dos irlandeses, da periferia que está avançando pelas sendas do progresso graças à intervenção do capitalismo inglês. O que se discute é uma questão decisiva, em primeiro lugar, para a própria classe operária inglesa, e, em segundo lugar, para toda a classe operária européia - afinal, os rumos do proletariado inglês e os destinos da revolução inglesa seriam decisivos para o que viria a acontecer na Europa.

O interessante no tratamento dado por Marx à questão irlandesa é que, pelo menos nesse caso, classe e nação, escalas nacional e internacional se articulam, em vez de se oporem, ou simplesmente serem manipuladas taticamente. Há algo de mais profundo que instaura a relação entre centro (Inglaterra), periferia (Irlanda) e mundo (Europa), e que Marx, de maneira inspirada, expressou da seguinte maneira: "repete-se na Inglaterra 
L U G A R , $\quad$ R E $\quad$ G I A

de nossos dias o que a antiga Roma mostrou em escala colossal. O povo que escraviza a outro povo forja suas próprias cadeias" (Karl Marx, Circular do Conselho Geral ao Conselho Federal da Suiça Francesa, apud Marx \& Engels, 1979, p.197).

Engels, ao que parece, também reviu profundamente sua posição. Em 1892, referindo-se à luta de poloneses e republicanos irlandeses, afirmava que estes tinham "não somente o direito, mas o dever de ser nacionais antes de ser internacionais [pois] é quando são bem nacionais que são internacionais da melhor maneira possível” (Haupt, 1974, p.19).

\section{NACIONALISMO E DIREITO À AUTODETERMINAÇÃO - NAÇÃO E CLASSE NO FINAL DO SÉCULO XIX}

Na virada do século XIX para o XX, explodem por toda parte tensões nacionais, seja na periferia extra-européia do capitalismo, em virtude da expansão colonial, seja na periferia imediata - Europa Oriental e Bálcãs -, onde começavam a ruir os pés de barro sobre os quais se apoiavam os três grandes impérios multinacionais: Império Russo, Império Austro-Húngaro e Império Otomano.

Os social-democratas, unificados na Internacional Socialista, vêem sua profissão de fé internacionalista ser desafiada. A inexistência de uma teoria (digna desse nome) marxista do Estado e a pobreza do patrimônio intelectual do marxismo sobre a questão nacional apenas agravam as dificuldades. Divisóes nacionais no interior dos Estados e dos próprios partidos, assim como reivindicações nacionalistas de vários povos desafiam, na teoria e na prática, a sacrossanta unidade internacional da classe trabalhadora.

O desenlace desse processo, do ponto de vista do movimento socialista, é conhecido. De um lado, a desagregação da II Internacional, cujas sessões nacionais vão aderir, em seus respectivos países, às políticas belicistas, ditas pudicamente de "defesa nacional", e que levariam o mundo à carnificina das trincheiras da Primeira Guerra Mundial. De outro lado, a Revolução Russa, sob a liderança dos bolcheviques, que haviam denunciado o que chamavam de capitulação dos social-patriotas.

Seria impossível recuperar todo o rico debate desse período. Tomei dois momentos desse processo que, a meu ver, ilustram à perfeição a diversidade e riqueza das teses em confronto: o debate que opôs Rosa Luxemburg e Lenin a respeito da Polônia e a polêmica travada no partido austríaco sobre soberania nacional e autonomia cultural.

No Congresso de 1896 da Internacional Socialista, delegada do Partido Social Democrata do Reino da Polônia, Rosa Luxemburg (1974) faz duro ataque ao nacionalismo polonês. Suas idéias essenciais podem ser sintetizadas pelas passagens seguintes:

Na sociedade de classes não há nação enquanto entidade sociopolítica homogênea; por outro lado, em cada nação há classes com interesses e "direitos antagônicos". (Ibidem, p.194.)

Quando se encontra na história das sociedades modernas lutas e movimentos "nacionais", por "interesses nacionais", são em geral movimentos de classe da camada burguesa dirigente. (Ibidem, p.195.)

[Em conseqüência,] Na questão das nacionalidades, um partido socialista ... deve considerar antes de mais nada o antagonismo das classes. (Ibidem, p.196.) 
Em conseqüência, argumentava Rosa Luxemburg, introduzir no programa socialdemocrata o direito das nações à autodeterminação seria aceitar o contrabando do ponto de vista nacionalista sob a bandeira do internacionalismo.

Defendendo a idéia de que os socialistas devem lutar intransigentemente pela igualdade das nacionalidades em instituiçōes democráticas, rejeita radicalmente que isso seja desejável, e, mesmo, possível nos marcos de um Estado nacional burguês. Por essa razão, a Internacional Socialista deveria colocar em seu programa a igualdade das nacionalidades, mas não o apoio à constituição de um Estado polonês soberano, que seria, necessariamente, expressão e instrumento da dominação de classe. ${ }^{3}$

A mesma questão vai estar no núcleo de uma polêmica no Partido Operário SocialDemocrata Russo, ao qual o Partido Polonês se havia filiado. Rosa Luxemburg questiona o artigo $\left(9^{\circ}\right)$ do programa do POSDR que defende a autodeterminação nacional, ou seja, o direito de toda nação a dispor de si mesma. Segundo Luxemburg, o princípio do "direito à autodeterminação" é abstrato e metafísico e reconhecê-lo implicaria subordinar o proletariado e o socialismo ao nacionalismo burguês. Certamente, afirma, os socialistas lutam pela igualdade e autodeterminação das nações, mas isso é uma utopia nos marcos do Estado burguês, onde, justamente, os povos, isto é, os trabalhadores são dominados e explorados por suas burguesias nacionais.

Lenin defende o Programa, partindo da afirmação de que a análise econômica da internacionalização do capital deve ser deixada de lado nesse debate, por tratar-se de questão democrática, a resolver-se na esfera da política (Lowy, 1974, p.370). Recusa a idéia de que o problema da autodeterminação de uma nação possa ser resolvido com a proposta de autonomia cultural nos marcos de um estado multinacional, como sugeria Rosa, na esteira dos austríacos cujas posições serão examinadas logo a seguir. Lenin também recusa entrar numa discussão, já presente em Engels, e retomada por Luxemburg, de que há estados viáveis - os grandes estados baseados em grandes nações - e estados inviáveis - os "povinhos primitivos" de Engels.

A questão, para Lenin, está no reconhecimento de que o internacionalismo só é possível se fundado na relação entre nacionalidades iguais em direitos. Ora, essa igualdade não é real se alguns povos têm o direito de estabelecer seu estado, enquanto a outros não é oferecida senão a autonomia cultural... ou mesmo o simples desaparecimento - seja pela assimilação seja pela violência. $\mathrm{O}$ reconhecimento do direito à autodeterminação não deve implicar, segundo Lenin, que os socialistas consagrem seus esforços à luta nacional, em vez de dedicá-los à luta de classe. Mas, como destacou Lowy (1974), Lenin é muito sensível para o potencial político da questão nacional e para a impossibilidade de qualquer neutralidade quando uma nação oprimida luta pela soberania contra um Estado opressor. A questão está no equilíbrio delicado entre defender o direito à autodeterminação das nações com o nacionalismo, equilíbrio que Lenin (1959, p.447) busca com curioso argumento:

Acusar os partidários da livre determinação, isto é, da livre separação das [nacionalidades para constituir um Estado soberano], de encorajarem o separatismo é tão absurdo e hipócrita quanto acusar os partidários da liberdade de divórcio de encorajar a destruição dos laços de família.

Penso ser possível afirmar que o líder russo buscava, de alguma maneira, preservar um espaço para a luta na escala nacional:

3 Rosa Luxemburg não deixa de denunciar os conservadores que, em outro contexto, usam, sob os aplausos de alguns socialistas, passagens em que Marx e Engels saudavam a luta nacional polonesa, e reivindica que, quando necessário, e contra todo dogmatismo que transforma verdades contingentes em verdades universais intocáveis, deve-se usar Marx para rever Marx. 
L U G A R , $\quad$ R E $\quad$ G I

Igualdade completa das naçóes; direito das nações a dispor delas mesmas; união dos operários de todas as nacionalidades: eis o programa nacional indicado aos operários pelo marxismo, pela experiência do mundo inteiro e pela experiência russa. (Ibidem, p.480.)

\section{NAÇÕES E ESTADO - O CULTURALISMO NO IMPÉRIO AUSTRO-HÚNGARO}

Outro rico processo de discussão, tanto teórica como política, desenrolou-se no interior do Partido Social-Democrata Austríaco, onde se destacam as contribuições de Renner e Otto Bauer.

Jurista e sociólogo, Renner, que chegou a chanceler austríaco de 1918 a 1920, se debruçou sobre a relação entre Nação e Estado. Em 1899, lançou um livro - Estado e Nação - no qual elaborava a seguinte tese: sendo a nação essencialmente uma comunidade cultural e lingüística, seus interesses estão, na verdade, aquém ou além dos interesses econômicos. Ora, a esfera da economia e dos interesses econômicos se internacionaliza a passos acelerados. Trata-se, portanto, de conceber um formato que contemple essa dupla dimensão: internacionalização da economia e permanência das culturas nacionais.

Sobre essa base, Renner rejeitava qualquer separatismo das naçôes do Império Austro-Húngaro. Como jurista, vai conceber e propor uma refundação do Império, de modo a afirmar seu caráter multinacional por meio do respeito à igualdade das nacionalidades e, sobretudo, do respeito à autonomia cultural. À noção de autodeterminação e soberania, Renner e o Partido Austríaco opunham a noção de autonomia. E não apenas reconheciam virtudes na organização do Estado imperial dual - austríaco e húngaro -, como defendiam que essas virtudes fossem aprofundadas, ampliadas, radicalizadas. As escolas deveriam adaptar-se a essa realidade e ensinar também em checo, croata e outras línguas. Separar as nacionalidades que já estavam unidas no Império seria empurrar para trás, e não para a frente, a luta internacionalista pela integração de todos os povos. Um império democratizado, respeitador das autonomias culturais, seria, de alguma maneira, um prenúncio do mundo socialista.

As posições de Renner foram adotadas pelo Congresso de Brunn, quando, pela primeira vez, um partido socialista assumia, formal e abertamente, um programa nacional. Esse propugnava a transformação da Áustria numa democrática federação de nacionalidades. No lugar do exclusivismo dual austro-húngaro, constituir-se-iam corpos autoadministrados de todas as nacionalidades do império, dotados de autonomia cultural e lingüística, respeitados em todos os territórios os direitos das minorias, garantidos por lei adotada pelo Parlamento federal.

Certamente o Congresso de Brunn inovava extraordinariamente, tendo em vista a tradição socialista-marxista. Separava a Nação do Estado e afirmava o valor da autonomia, em detrimento da soberania. E, numa espécie de pós-modernismo avant la lettre, incorporava como essenciais o multiculturalismo e o respeito à diversidade.

Em Marx, e no Manifesto, esse trabalho de unificação universal do gênero humano, iniciado pelo capital sob a égide do mercado mundial, seria completado pela vitória do proletariado socialista. No Partido Austríaco, em vez da marcha inexorável para o apagamento de todas as fronteiras e toda a diversidade, o caminho a ser trilhado seria o da valorização dessa diversidade. 


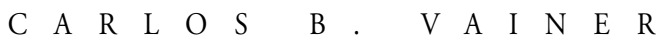

Duas utopias, ambas reivindicando o socialismo: numa, o universalismo se realiza pela unificação num único gênero humano e numa única literatura universal, como prenunciava o Manifesto; noutra, a utopia do universalismo se realiza pela convivência do diverso.

Em Otto Bauer essa segunda utopia vai ser radicalizada. Mais que comunidade cultural e lingüística, a Nação é agora definida como "comunidade de destino". Em outras palavras: a nacionalidade, o pertencimento e a identidade nacionais não estão ancorados apenas no passado - patrimônio cultural e lingüístico herdados -, mas também, e sobretudo, no futuro, num destino (imaginário) compartilhado. A Nação e os particularismos deixam de ser o adversário a combater, para transformarem-se em objetivo a alcançar no embate com a vocação homogeneizadora do mercado mundial. Cabe aos socialistas preservar as nações e suas culturas, em vez de completar a obra destrutiva do capital.

O socialismo internacional deve compreender a diferenciação nacional dos métodos de luta e da ideologia em seu seio como o resultado de seu crescimento (...) A tarefa da Internacional deve e pode ser, não o nivelamento das especificidades nacionais, mas a realização da unidade internacional na diversidade nacional. (Bauer apud Haupt, 1974, p.48.)

Para Bauer, a diversidade das nações, e portanto a existência mesma das nações, é um projeto de futuro, posto que, até hoje, os trabalhadores estiveram excluídos da Nação. A educação e a superação do capitalismo como envelope econômico da sociedade permitirão o pleno florescimento das naçôes "como comunidade da educação, do trabalho e da cultura”. A Nação e seu (re)encontro com os trabalhadores seria, pois, um dos objetivos dos socialistas.

\section{A COMUNA DE PARIS E O LOCALISMO FEDERALISTA REVOLUCIONÁRIO}

Até aqui tratamos de debates que tiveram como foco central o par nacionalismo versus internacionalismo, que também, em muitos momentos, se apresentou como par nação versus classe. O debate do século XIX, porém, não se limitou a examinar as relações entre essas duas dimensões e escalas da ação política. O episódio revolucionário da Comuna de Paris enriqueceu enormemente esse debate justamente por haver introduzido, de maneira trágica e heróica, a questão da organização federal do que poderia ser uma república democrática fundada nas organizaçōes sociais locais.

Na primavera de 1871, durante 72 dias, na tradição de outros tantos levantes, o povo de Paris, que se encontrava cercado pelas tropas prussianas após a derrota e a queda de Napoleão III, invadiu o Hotel de Ville (sede da prefeitura) e assumiu o poder. Sob a liderança dos blanquistas e, secundariamente, proudhonianos e bakuninistas, os communards organizaram o primeiro poder revolucionário a adotar uma ideologia abertamente classista - proletária. Se na área da legislação social, da educação e da emancipação das mulheres a Comuna mostrou-se extraordinariamente criativa, ultrapassando muitas das propostas e dos projetos que os revolucionários haviam concebido e divulgado em seus panfletos e obras teóricas, também no que concerne à organização e configuração escalar ela abriu novos campos de discussão.

Poder-se-ia começar por chamar a atenção para o próprio nome desse núcleo de poder revolucionário - hesito em chamá-lo de Estado. Comuna: mais que um simples no- 
L U G A R , $\quad$ R E $\quad$ G I A

me, mais que um mero remetimento ao Conselho Geral de Paris eleito democraticamente, a adoção orgulhosa do nome trazia consigo toda uma concepção e programa de organização social. Contra o Estado autocrático centralizado e centralizador - do poder e da riqueza -, os revolucionários conclamam todas as comunas a se insurgirem contra o poder central e a assumirem o poder em suas respectivas jurisdições, a fim de que se possa constituir uma livre federação de livres comunas. A esse respeito, escreveu Marx (1871, p.25) - cujos partidários ligados à Associação Internacional dos Trabalhadores, não tiveram nenhum papel de relevo na Comuna de Paris:

a Comuna de Paris havia de servir de modelo a todos os grandes centros industriais da França. Uma vez estabelecido em Paris e nos centros secundários o regime comunal, o antigo governo centralizado teria de ceder lugar também nas províncias ao governo dos produtores pelos produtores. No breve esboço de organização nacional que a Comuna não teve tempo de desenvolver, diz-se claramente que a Comuna deveria ser a forma política inclusive das menores aldeias do país (...)

Esse ideal de república federativa comunal, como chamou atenção Korsch (1929), estava muito mais próximo do federalismo de blanquistas e proudhonianos que das teses marxistas. Na discussão sobre o caráter da Comuna, Marx vai sugerir que ela não recompõe nem resgata as características da comuna na qual, ainda sob o domínio do feudalismo, a burguesia deu seus primeiros passos para se constituir como classe. Escreveu Marx:

Em geral, as criações históricas completamente novas estão destinadas a ser tomadas como uma reprodução de formas velhas, e mesmo mortas, da vida social, com as quais podem ter certa semelhança. Assim, esta nova Comuna, que vem destruir o poder estatal moderno, foi confundida com uma reprodução das comunas medievais, que precederam imediatamente esse poder estatal e logo lhe serviram de base. (Ibidem, p. 28.)

No dizer de Korsch (1929), a comuna,

longe de representar apenas uma forma burguesa de governo mais antiga que o parlamento, foi - desde a sua origem no século XI até ao seu apogeu, o grande movimento burguês da Revolução francesa de 1789-93 - nem mais nem menos que a manifestação concreta e mais pura do ponto de vista de classe da luta que a burguesia, na época classe revolucionária, conduziu sob as mais diversas formas, durante todo este período, com vistas a abater a ordem feudal até então predominante, e substituí-la pela sua ordem própria, a ordem social burguesa.

Assim, em Paris de 1871, a comuna era vista como uma "nova" comuna: fora no passado a estufa em que teria ocorrido a gênese da burguesia revolucionária, constituía-se agora em espaço de afirmação do proletariado revolucionário. $\mathrm{O}$ interessante é que, com a Comuna de Paris, em todos os sentidos, uma nova e revolucionária escala ingressa no debate: a escala urbana, local ou comunal.

Se somos tentados a uma assimilação da escala comunal ao que costumamos reconhecer hoje como local, vale a advertência de que a comuna revolucionária nada tem a ver com nenhum tipo de comunidade, fundada em laços de sangue, língua, cultura ou territoriais. Ela é uma comunidade de cidadãos, e não de linhagens ou de vizinhos. 
Da mesma maneira, se encontramos aqui também a forma federativa proposta, alguns anos mais tarde, por Renner e Bauer, a federação dos communards é de base territorial, e não de base nacional, étnica e/ou cultural. É ilustrativo e cheio de ensinamentos sobre esse significado de "comuna" o seguinte episódio. Léo Frankel, operário joalheiro húngaro e judeu foi eleito para uma vaga no Conselho Geral da Comuna. O Comitê Eleitoral, a respeito, deliberou o que segue:

Considerando que a bandeira da Comuna é a bandeira da República universal; considerando que toda cidade tem o direito de dar o título de cidadão aos estrangeiros que a servem ... a comissão é de parecer que os estrangeiros podem ser admitidos, e propõe a admissão do cidadão Frankel. (Apud La Commune de Paris, http://lacomune.club.fr/pages/parent.html) ${ }^{4}$

Trata-se, decididamente de uma nova e original escala, embora com passagem meteórica pela história. Interessante ver como Marx (1871, p.35) imediatamente a incorpora em seu esquema escalar.

A Comuna era, pois, a verdadeira representação de todos os elementos sãos da sociedade francesa e, portanto, o governo nacional autêntico. Mas, ao mesmo tempo, como governo operário e campeão intrépido da emancipação do trabalho, era um governo internacional no pleno sentido da palavra. Ante os olhos do exército prussiano, que havia anexado à Alemanha duas províncias francesas, a Comuna anexou à França os operários do mundo inteiro. ${ }^{5}$

\section{CONSIDERAÇÕES FINAIS - DE VOLTA AO DEBATE CONTEMPORÂNEO SOBRE ESCALAS}

Apesar dos limites da exposição, espero ter sido possível, pelo menos, mostrar a riqueza que uma exploração histórica do tema das escalas da ação política pode trazer para o debate contemporâneo. Penso ter sido possível mostrar como, de fato, os embates políticos e ideológicos mobilizam e acionam, instauram e rompem escalas, num processo em que narrativas escalares estruturam e fundamentam estratégias e táticas, configurando arenas e objetos de disputa. Não apenas as escalas se transfiguram, como seu próprio significado e nomeação indicam redefinições de sujeitos e relações.

A historicidade dos processos escalares está posta como uma permanente advertência para que evitemos o congelamento confortável das escalas, que, por exemplo, faz de termos como "lugar" ou "local" noçôes absolutamente ideológicas, destituídas de qualquer consistência conceitual. De que "local" se fala quando se fala de desenvolvimento local: do município brasileiro, da aldeia tailandesa, da comunidade tribal indiana, do county norte-americano, da comuna francesa? ${ }^{6}$

Com essa convicção reforçada pelo exercício realizado, é possível retomar uma idéia trabalhada no início deste texto: os desafios que a reconfiguração contemporânea das escalas coloca para todos os que militamos e pesquisamos no campo do Planejamento Urbano e Regional. Planejamento nacional, regional, local? De que se trata? Como se definem e relacionam? Sem uma visão minimamente consistente sobre essas questôes, sem ao menos instaurar o debate sistemático a respeito, estaremos num jogo de cabra-cega onde apenas têm os olhos descobertos as grandes corporações globais, que articulam e intervêm em todas as escalas, à luz de estratégias e táticas transescalares.

4 Vale a pena, neste ponto, citar o que escreveu Hobsbawm (1990, p.33) a respeito de experiência similar, ocorrida no calor da Revolução Francesa, quando o anglo-americano Thomas Paine foi deputado eleito para a Convenção Nacional, em 1792: "a característica do povo-nação vista de cima era o fato de representar o interesse comum em oposição ao interesse privado e o bem comum em oposição ao privilégio ... Do ponto de vista revolucionário as especificidades étnicas eram secundárias como acontecerá mais tarde com os socialistas".

5 Os limites deste trabalho impedem que exploremos também os desdobramentos desse debate, que vão estar presentes, na Revolução Russa, na discussão e implantação da organização do novo Estado soviético e de suas relações com a questão das nacionalidades. $\mathrm{E}$ mais tarde, nas elaborações dos partidos comunistas, incluindo o brasileiro, e, por ele, toda a intelligentzia progressista brasileira, no tratamento das questões escalares.

6 Certamente, há que enriquecer essas explorações, na direção de ler criticamente também outros participantes do debate do século XIX: jacobinos, liberais, anarquistas - talvez sobretudo estes últimos, de marcante presença na Comuna, na discussão que se the seguiu e, de modo geral, na denúncia do estado centralista e centralizador. 
Carlos B. Vainer é professor do Instituto de Pesquisa e Planejamento Urbano e Regional da Universidade Federal do Rio de Janeiro Ippur/UFRJ.

E-mail: cvainer@uol.com.br

Artigo recebido em outubro de 2006 e aprovado para publicação em novembro de 2006.
L U G A A , $\quad$ R E $\quad$ G I A

Os pesquisadores e intelectuais não podem resolver todos os problemas, mas têm a obrigação de, pelo menos, contribuir para que eles sejam postos na mesa diante dos múltiplos agentes sociais que têm muito a perder ou a ganhar conforme as escalas que se imponham e as correlações de forças resultantes.

Se, como sugere Swyngedouw, a reconfiguração das escalas do poder - re-scaling of power - é um dos elementos definidores da contemporaneidade, a tarefa da objetivação e análise dos embates nessa arena é decisiva. Localismos, nacionalismos, regionalismos, globalismos, todos esses modelos e projetos devem ser incessantemente interpelados. Afinal de contas, o poder, mais do que nunca, não está nem no local nem no regional, nem no nacional nem no global... mas na capacidade de articular escalas, de analisar e intervir de modo transescalar.

Por isso mesmo, a questão da "escala da agência" e, em particular, a "escala da ação política" parece ser crucial tanto para aqueles que querem compreender o mundo contemporâneo quanto para aqueles que querem transformá-lo.

\section{REFERÊNCIAS BIBLIOGRÁFICAS}

BOURDIEU, P. Contre-feux: propos pour servir à la résistance contre l'invasion neolibérale. Paris: Éditions Líber - Raisons d’Agir, 1998.

CASTELLS, M. The world has changed: Can planning change? Keynote Speech, ACSP Annual Meeting, Austin, Texas, November, 1990 (mimeogr.).

CASTRO, I. E. de. O problema da escala. In: CASTRO, I. E. de et al. (Org.) Geografia: conceitos e temas. 7.ed. Rio de Janeiro: Bertrand Brasil, 2005. p.117-40. Solidariedade territorial e representação: novas questōes para o pacto federativo nacional. Território, n.2, v.1, p.33-42, jan./jul. 1997.

HARDT, M.; NEGRI, A. Império. Rio de Janeiro: Record, 2001.

HAUPT, G. Les marxistes face à la question national: l'histoire du problème. In: HAUPT, G. et al. Les marxistes et la question nationale. 1848-1814. Paris: François Maspéro, 1974. p.9-61.

HOBSBAWM, E. J. Naçôes e nacionalismo desde 1780. programa, mito e realidade. Rio de Janeiro: Paz e Terra, 1990.

KORSCH, K. A comuna revolucionária (I) - 1929. Disponível em: <www.geocities.com /autonomiabvr/comunare.html (2005-10-6)>.

A comuna revolucionária (II) - 1931. Disponível em: <www.geocities.com /autonomiabvr/comunare.html (2005-10-6)>.

LA COMMUNE DE PARIS. Disponível em: http://lacomune.club.fr/pages/ parent.html.

LACOSTE, Y. La géographie, ça sert d'abord à faire la guerre. Paris: Maspéro, 1976. LENIN, V. Du droit des nations à disposer d'elles-mêmes. In: Oeuvres. Paris/Moscou: Éditions Sociales/Éditions en Langues Étrangères, 1959. p.415-81.

LOWY, M. Le problème de l'histoire: remarques de théorie et de méthode. In: HAUPT, G. et al. Les marxistes et la question nationale. 1848-1814. Paris: François Maspéro, 1974. p.370-91.

LUXEMBURG, R. La question nationale et l'autonomie. In: HAUPT, G. et al. Les marxistes et la question nationale. 1848-1814. Paris: François Maspéro, 1974. p.185-203. 


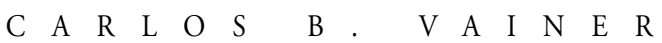

MARX, K. The British rule in India. New York Daily Tribune, june 25, 1853. Disponível em: Marxists Internet Archives, <www.marxists.org>. . La Guerra Civil en Francia. Manifiesto del Consejo General de la Associación Internacional de los Trabajadores. Disponível em: <http://www.marists.org/ espanol/m-e/1870s/gcfran/guer.htm>. [1871]

MARX, K.; ENGELS, F. Manifesto do Parido Comunista. Fortaleza: Forgrel, s.d. [1848].

Imperio y colonia: escritos sobre Irlanda. México: Ediciones de Pasado y Presente, 1979.

OLIVEIRA, F. de. Elegia para uma re(li)gião: Sudene, nordeste, planejamento e conflitos de classes. Rio de Janeiro: Paz e Terra, 1977.

SMITH, N. Desenvolvimento desigual: natureza, capital e a produção do espaço. Rio de Janeiro: Bertrand Brasil, 1988.

. Homeless/global: scaling places. In: BIRD, J. et al. (Ed.) Mapping the futures. local cultures, global change. London/New York: Routledge, 1993. p.87-119. SWYNGEDOUW, E. Neither global nor local: "glocalization" and the politics of scale. In: KEWIN, R. C. (Ed.) Spaces of globalization: reasserting the power of the local. New York/London: The Guilford Press, 1997. p.137-66.

WALLERSTEIN, I. Unthinking social science. the limits of Nineteenth-Century paradigms. Cambridge, UK: Polity Press, 1991.

A B S T R A C T Drawing from a theoretical review of the notion of scale and an historical approach of the socialist debate on nationalism and internationalism in the 19th century, this article intends to shed light on the contemporary debate about the scale of political agency and planning. Denying the possibility that any transforming strategy could be inscribed in an unique and privileged scale - local, regional, national or global -, the article suggests that power, more than ever, is not placed on the local, on the regional, on the national, nor on the global scales... but in the capacity to articulate scales, to analyse and intervene in a transscale manner.

K E Y W O R D S Scale; planning; political agency. 